\title{
UMA DISCUSSÃO SOBRE CORROSÃO EM CONCRETO ARMADO DE UMA PASSARELA
}

\author{
Felipe Eduardo dos Santos \\ Engenheiro Civil pelo CEFET-RJ \\ fellipeesantos@yahoo.com.br
}

\begin{abstract}
Andrea Sousa da cunha Fernandes
Mestre em Ciências pela UFRJ, Rio de Janeiro, RJ, Brasil

Professora do Departamento de Engenharia Civil - CEFET/RJ

andreascunha@gmail.com
\end{abstract}

José Luiz Fernandes

Prof. Titular do CEFET-RJ - Unidade Maracanã, Rio de Janeiro, RJ, Brasil

jluizfernandes@gmail.com

Clézio Thadeu de Souza Dutra

Prof. Associado do CEFET-RJ - Unidade Maracanã, Rio de Janeiro, RJ, Brasil

clezio@coneeng.com.br

\begin{abstract}
RESUMO
O presente artigo se propõe discutir sobre a corrosão em estruturas de concreto armado, através de uma revisão do tema, sobre o que é a corrosão, causas, mecanismos de proteção, análise e recuperação de estruturas com essa patologia. Além do mais foi realizado um estudo de caso em uma localizadas no Município de Duque de Caxias, região metropolitana do Rio de Janeiro, onde foram observados diversos problemas devido a corrosão nos pilares desta estrutura. Conclui-se que a falta de cobrimento ideal na construção de um estrutura, aliada a falta manutenção adequada, durante a vida útil da estrutura, facilita a ocorrência da corrosão.
\end{abstract}


Palavras chave: Corrosão. Estruturas de Concreto armado. Passarelas

\title{
A DISCUSSION ON CORROSION IN ARMED CONCRETE OF A WALKWAY
}

\begin{abstract}
This article proposes to discuss corrosion in reinforced concrete structures, through a review of the theme, about what corrosion is, causes, protection mechanisms, analysis and recovery of structures with this pathology. Furthermore, a case study was carried out in one located in the Municipality of Duque de Caxias, metropolitan region of Rio de Janeiro, where several problems were observed due to corrosion in the pillars of this structure. It is concluded that the lack of ideal covering in the construction of a structure, allied to the lack of adequate maintenance, during the useful life of the structure, facilitates the occurrence of corrosion.
\end{abstract}

Key words: Corrosion. Structures of reinforced concrete. Walkways

\section{INTRODUÇÃO}

O presente artigo se propõe a abordar e discutir sobre a corrosão em Estruturas de Concreto Armado, através de uma revisão do tema, sobre o que é a corrosão, causas, mecanismos de proteção, análise e recuperação de estruturas com essa patologia.

Segundo Gentil (2011) corrosão é definida como a deterioração de um material, geralmente metálico, por ação química ou eletroquímica do meio ambiente, aliada ou não, a esforços mecânicos. Diversas podem ser as causas da ocorrência da corrosão, tais como, a carbonatação do concreto, a reação álcalis-agregado, corrosão negra (ausência de oxigênio), corrosão bacteriana, por "correntes vagabundas", ataque de ácidos e ação de íons cloreto.

A Prevenção da corrosão em estruturas de engenharia torna-se, nos dias atuais, um assunto de extrema importância, visto que, há um aumento considerável no projeto, devido aos custos de manutenção. Segundo Andrade e Silva (2005) as patologias em es- 
truturas de concreto devido a dilatação dos materiais, ação de intempéries entre outros. Ocorre que atualmente, antes dos 20 anos de existência as edificações já necessitam de manutenções corretivas para aumento da vida útil. Segundo Brandão (1999) atualmente a deterioração precoce das estruturas estão ligadas diretamente a uma somatória de fatores, dos quais citam-se: inadequação dos materiais, má utilização da obra, agressividade do meio ambiente, ineficiência e falta de manutenção. Segundo Alani, Peterson e Chapman (2001) ilustram a evolução dos custos de manutenção conforme a depreciação com o tempo, de forma que o custo de manutenção com o tempo apresenta um crescimento exponencial.

Para prevenir as estruturas quanto a corrosão existem algumas técnicas como proteção catódica, dessalinização e realcalinização, revestimento do concreto e argamassa polimérica, armaduras de aço-carbono revestidas, e de aço inoxidável. Caso não sejam aplicadas as técnicas de prevenção tenham sido insuficientes, deve ser feita a análise dessa estrutura, para indicar as causas e possíveis soluções para o problema identificado, como a inspeção visual, ensaio de esclerometria, ensaio de profundidade de carbonatação, ensaio de reflectometria no domínio do tempo, ensaio de impedância eletroquímica e ensaio de migração de cloretos

Este trabalho apresenta um estudo de caso de uma passarela localizada no Município de Duque de Caxias, região metropolitana do Rio de Janeiro, onde foram observados diversos problemas devido a corrosão nessas estruturas. Conclui-se que a falta de cobrimento ideal na construção de um estrutura, aliada a falta manutenção adequada, durante a vida útil da estrutura, facilita a ocorrência da corrosão, que se não tratada, pode chegar ao colapso.

\section{REVISÃO BIBLIOGRÁFICA}

Uma estrutura de concreto armado é composta por concreto e aço. Segundo Rocha (2015) as armaduras de aço inseridas no concreto estão, em princípio, protegidas e passivadas contra o risco de corrosão, devido a proteção alcalina presente nos poros de concreto, pH em torno de 12,5. Porém segundo Ribeiro et al. (2014) quando essa proteção se rompe, se não tratada, a estrutura estará propensa a possibilidade de ser atacada por corrosão. 
De acordo com Gentil (2011) define-se corrosão como a deterioração de um material, geralmente metálico, por ação química ou eletroquímica do meio ambiente aliada ou não a esforços mecânicos.

Gentil (2011) define os 5 principais tipos de corrosão. a) Corrosão Uniforme: é aquela em que ocorre em toda a extensão da superfície da armadura, gerando perda uniforme de sua espessura; b) Corrosão por pite: é aquela que se caracteriza por pontos ou pequenas áreas de corrosão na superfície do metal produzindo os chamados pites, que são cavidades que apresentam o fundo em forma angulosa e geralmente é tem uma profundidade maior do que o seu diâmetro; c) Corrosão intergranular: é aquela em que a corrosão ocorre entre os grãos da rede cristalina do metal, que pode perder as suas propriedades mecânicas e sobre a menor solicitação mecânica ele pode vir a fraturar; d) Corrosão intragranular ou transgranular: é aquela em que a corrosão ocorre nos grãos da rede cristalina do metal, que pode perder as suas propriedades mecânicas e sobre a menor solicitação mecânica ele pode vir a fraturar; e) Corrosão por empolamento pelo hidrogênio: é aquela em que o hidrogênio atômico penetra no metal e se difunde pelos vazios do material, onde se transforma em hidrogênio molecular $\mathrm{H}_{2}$, formando bolhas e consequente fragilizando o metal.

A corrosão que se apresenta na armadura de aço em uma estrutura de concreto armado ocorre devido a um processo denominado eletroquímico, este processo ocorre em meio aquoso. Marques (2015, p. 21 apud CASCUDO, 1997, p.18) diz que a corrosão aquosa, trata de um ataque de natureza eletroquímica, que ocorre no meio aquoso, desencadeado pela formação de uma pilha de corrosão, com eletrólito e diferença de potencial entre trechos da superfície do aço. O eletrólito forma-se a partir da presença de umidade no concreto em contato com a armadura. Este é o tipo de reação mais encontrado em estruturas de concreto armado.

Vilas Boas (2004) apresenta um fluxograma, ilustrado a figura 1, das principais causas químicas de deterioração no concreto 
Figura 1 - Causas químicas da deterioração do concreto

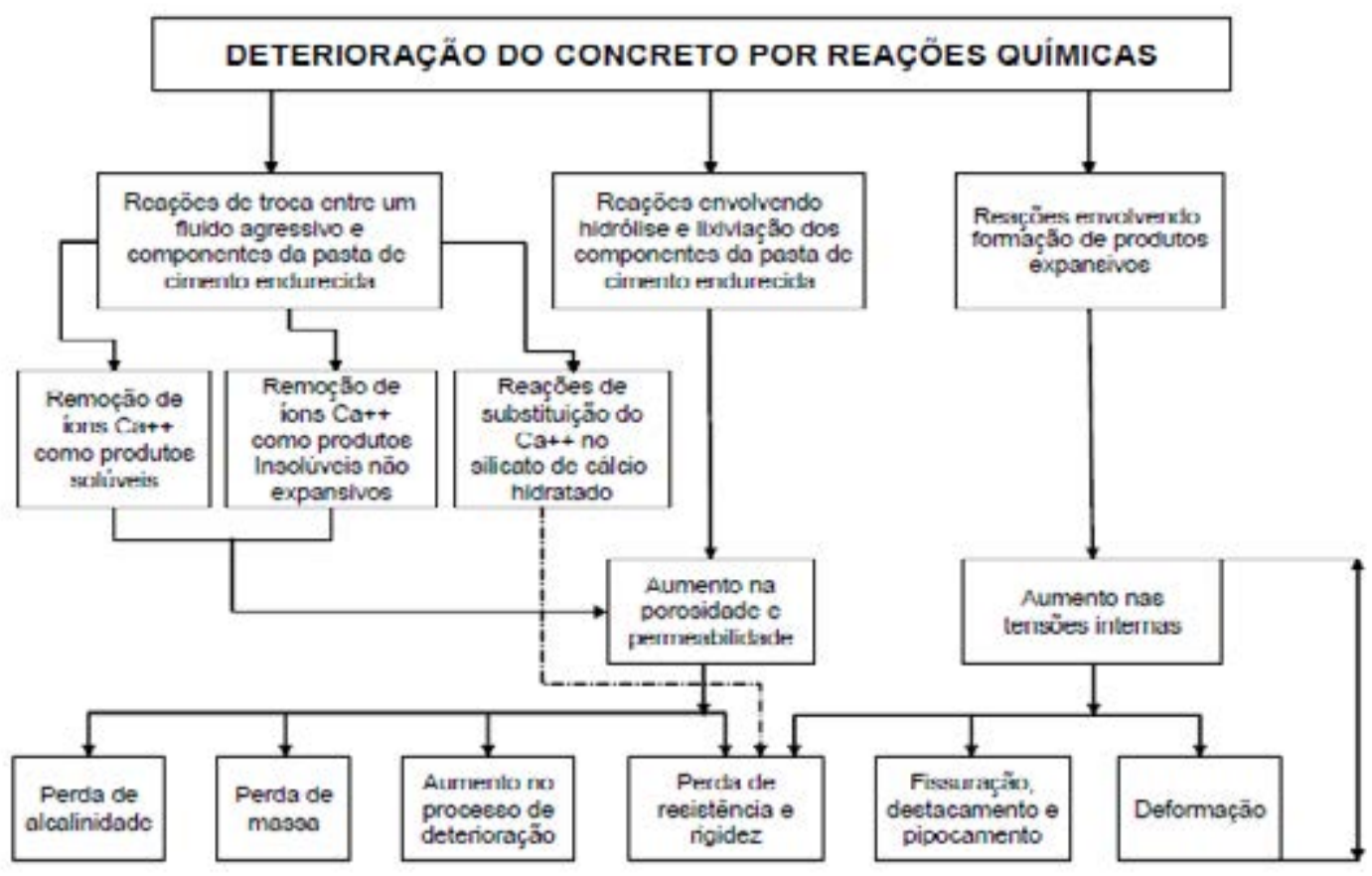

Fonte: (Vilasboas, 2004)

Ribeiro et al. (2014) afirmam que a corrosão provoca a diminuição da seção da armadura e fissuração no concreto. A ocorrência das fissuras são devido aos produtos da corrosão ocuparem um espaço maior que o aço de origem. Segundo Pellizzer (2015) afirma que as fissuras geradas pelas tensões de expansão da armadura de aço corroída se estabelecem em direção paralela a barra e vão aumentando de acordo com a evolução do processo de corrosão, como ilustrado na figura 2. 
Figura 2 - Evolução do processo de corrosão

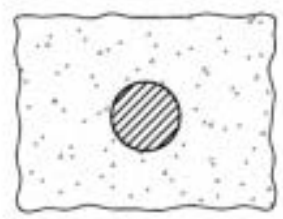

Antes de corrosåo

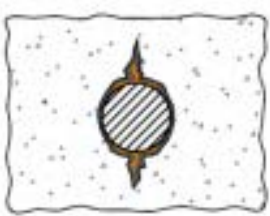

Acúmulo dos produtos das reações da corrosão

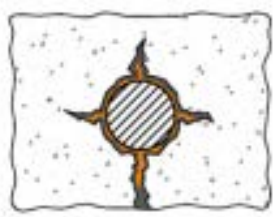

Avanço da corrosấo Fissuras na superficie e manchas

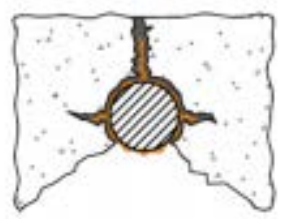

Eventual lascamento Barra corroida

Fonte: (Pellizzer, 2015)

Monteiro (2002) considera a corrosão da armadura devido a ação de íons cloretos como um dos mais sérios problemas das estruturas de concreto armado. Os íons cloreto podem ser introduzidos no concreto de diversas formas como a contaminação da água ou da areia presentes no concreto e/ou podem penetrar a partir do exterior da estrutura quando expostas em ambientes que o contenham.

Existem diversas formas de inibir ou reduzir os efeitos da corrosão, Freire (2005) cita por exemplo o método eletroquímico (proteção catódica e anódica), o isolamento da armadura e o uso de inibidores de corrosão. Ribeiro et al. (2014) cita o revestimento do concreto (orgânico, concreto impermeável e/ ou argamassa polimérica) como um método de proteger também a armadura da corrosão.

Araújo, Moreira e Panossian (2014) citam que há cinco formas de aumentar a durabilidade do concreto armado frente a ação da corrosão em suas armaduras, sendo elas: 1) aplicação de um potencial externo (proteção catódica), 2) adição de inibidores no concreto armado, 3) desenvolvimento de concretos mais resistentes a corrosão, 4) revestir a superfície da armadura 5) substituir a armadura de aço comum por uma mais resistente a corrosão.

A corrosão nas estruturas de concreto armado por ser uma patologia que quando os sintomas aparecem, já está iniciada e bastante propagada deve ser muito bem analisada e monitorada, para isso há diversas técnicas de avaliação da proteção da armadura (avaliação do concreto de recobrimento) até avaliações e monitoramento da armadura no interior do concreto. As principais técnicas são: a) Ensaio de inspeção Visual, b) Ensaio de esclerometria, c) Ensaio de profundidade de carbonatação, d) Ensaio de TDR, e) 
Ensaio de impedância eletroquímica, f) Ensaio de migração de íons cloreto.

A inspeção visual é uma das formas mais usuais de avaliação de como se encontra o estado de corrosão nas obras em concreto armado. Na inspeção visual algumas anomalias no concreto são comumente observadas, tais como, a presença de broca ou concreto segregado na estrutura, perda de concreto por ataque químico (lixiviação, erosão, cavitação, atrito ou abrasão), perda da integridade do concreto devido a atuação de forças internas ou externas, armadura exposta por anomalias ou falta de cobrimento adequado, fissuras, deformação da estruturas, porosidade superficial e/ou manchas de oxidação. (ARAÚJO e PANOSSIAN, 2011)

O ensaio de esclerometria mede a dureza superficial do concreto e fornece elementos para que seja avaliado a qualidade do concreto endurecido. Para realizar o ensaio é necessário um esclerômetro de reflexão, que consiste em uma massa-martelo impulsionada por uma mola que se choca através de uma haste na superfície de ensaio. A reflexão do impacto no aparelho fornece diretamente no aparelho o índice de esclerométrico referente ao recuo do martelo. Este ensaio é baseado na NBR 7584:2012,

O ensaio de profundidade de carbonatação indica que é necessário retirar uma amostra a seco de concreto ortogonal a estrutura, após a retirada dessa amostra deve-se quebrar um pedaço da amostra (por flexão) e aspergir o indicador nela, normalmente se utiliza como indicador $1 \mathrm{~g}$ de fenolftaleína dissolvida em $50 \mathrm{~g}$ de álcool e $50 \mathrm{~g}$ de água. (RIBEIRO et al., 2014) O indicador fenolftaleína pode apresentar as seguintes colorações: a) Incolor para pH inferior a 8,3; b) Vermelho carmim para ph > 9,5; c) Entre rosa e vermelho para $\mathrm{pH}$ entre 8 e 9 . A partir desse resultado deve-se medir a profundidade de carbonatação com o auxílio de uma régua. (ANDRADE, COSTA e SILVA, 2008)

O ensaio de reflectometria no domínio do tempo (Time Domain Reflectrometry - TDR) tem como vantagem poder detectar e medir com precisão a extensão da área afetada pela corrosão, através de um impulso curto de corrente num condutor, se nesse condutor houver uma impedância uniforme ele não gera reflexões, zonas de corrosão na armadura alteram a impedância dos metais nessas zonas o que gera ecos eletromagnéticos que são captados por um fio sensor. (RIBEIRO et al., 2014)

O ensaio de impedância eletroquímica consiste em aplicar um sinal alternado de pequena amplitude (5 a $20 \mathrm{mV}$ ) a um eletrodo (armadura) inserido em um eletrólito 
(concreto), então compara-se a perturbação gerada pelo sinal aplicado com a resposta do eletrodo, pela medida de mudança de fase e amplitude dos componentes da corrente. Essa técnica fornece a velocidade da corrosão, caracteriza o estado da armadura e a morfologia da corrosão e permite o acompanhamento do estado passivo ou ativo ao longo do tempo. (FREIRE, 2005)

O ensaio de migração de cloretos é utilizado para a deteç̧ão da migração de íons cloreto no interior do concreto. (HELENE, 1993) Este ensaio é realizado mediante aplicação de diferença de potencial eletroquímico no concreto inserido entre duas células, a primeira célula é a catódica contendo uma solução de cloretos e a segunda uma célula anódica, sem cloretos. (SANTOS, 2006)

\section{DISCUSSÃO DO TEMA E RESULTADOS}

\section{1 - Histórico}

Neste trabalho será analisada uma passarela localizada, na cidade de Duque de Caxias/RJ. Esta passarela, faz a interligação sobre a via férrea entre as ruas Prefeito José Carlos Lacerda, e Almirante Tamandaré, na esquina com a Rua General Gurjão. A passarela fica próximo ao Hospital Infantil Ismélia da Silveira e faz a ligação entre as feiras de domingo na Cidade de Duque de Caxias, além de ter um ponto de ônibus de diversas linhas intermunicipais próximo a passarela, o que gera o grande número de tráfego de pessoas por dia, com um número excessivo de pessoas transitando aos domingos. (SANTOS, 2018) A figura 3, ilustra uma vista da passarela pela Rua Almirante Tamandaré. 
Figura 3 - Vista da passarela pela Rua Almirante Tamandaré

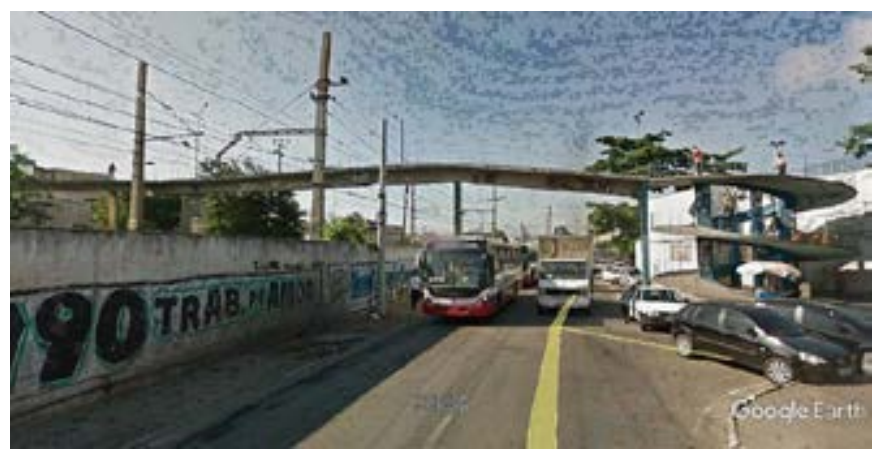

Fonte: (Google Earth, 2018)

A figura 4, ilustra uma vista da passarela em dia de feira com ambulantes e um grande número de pedestres transitando.

Figura 4 - Vista da passarela em dia de Feira

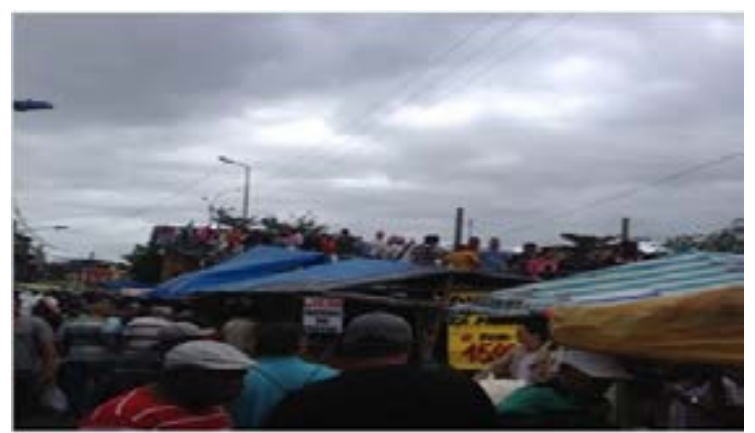

Fonte: (Engenheiro Rodrigo Faur, 2015)

3.2 Características técnicas da passarela

A passarela em estudo é feita em Concreto Armado e é composta de uma rampa reta na rua Prefeito José Carlos Lacerda com uma viga central e 07 pilares e laje, um tabuleiro composto de uma viga central e 02 pilares e laje, e uma ram- 
pa circular com 05 pilares, viga no raio interno da curvatura e laje em balanço.

\subsection{Problemas encontrados na passarela}

Para esta passarela foram encontrados dois boletins de ocorrência (2015 e 2016), que exemplificam os problemas visualmente encontrados na passarela.

No Boletim de Ocorrências $N^{\circ}$ 00776/2015, foi relatado que a passarela apresentava as seguintes alterações:

"foi constatado o mal estado de conservação, pois apresenta desprendimento de concreto, no piso e no fundo da laje da rampa de acesso, nos pilares e no rodapé, em concreto, deixando exposta a armadura da estrutura, rachadura na argamassa da alvenaria de vedação existente na rampa de acesso, princípio de corrosão na base do poste de iluminação, e falta de guarda corpo em diversos pontos da passarela, deixando em situação de risco os usuários da passarela."

No Boletim de Ocorrências $N^{\circ}$ 01053/2016, foi relatado que a passarela apresentava as seguintes alterações:

"foi constatado o mal estado de conservação, pois a mesma apresenta desagregação, oxidação da armadura e perda de área útil do concreto armado, no piso, fundo da laje da rampa de acesso, nos pilares e no rodapé, com armadura exposta e alta perda de resistência, rachadura na argamassa da alvenaria de vedação existente na rampa de acesso, princípio de corrosão na base do poste de iluminação, falta de guarda corpo em diversos pontos da passarela, e vibração excessiva na intercessão da rampa com o vão principal. A passarela recebe alta carga móvel durante o final de semana, pois existe uma feira livre nas intermediações em todos os domingos."

Nos dois Boletins de Ocorrências a Subscretaria Municipal de Defesa Civil solicitou que fossem realizadas obra de reparo e/ou reforço estrutural da passarela. 
Em março de 2018 pôde-se observar que a passarela continua sem a manutenção solicitada pela Defesa Civil e apresenta desplacamento e fissuras do concreto de cobrimento, perda da seção e ruptura do aço em todos os pilares, com seus graus mais altos de deterioração há cerca de $1,20 \mathrm{~m}$ do chão e diversos pontos de corrosão no tabuleiro; as possíveis causas são a carbonatação do concreto e a corrosão do concreto armado, possivelmente, por ataque de cloretos.

\subsection{Discussão dos problemas encontrados}

As causas descritas no item 3.3 são potencializadas pela falta de cobrimento ideal para estruturas ao ar livre, a grande presença de urina nos pilares e a falta de manutenção e revestimento de proteção adequado desses elementos estruturais.

Para efeitos de localização dos pilares da passarela, serão considerados os pilares da rampa reta na Rua Prefeito José Carlos Lacerda nomeado de Pilar 01 (P1) ao Pilar 08 (P8) (Figuras 5 e 6). (SANTOS, 2018)

No sentido de subida, sendo o P1 no início da rampa e o P8 no fim da mesma; P9, P10 e P11 (Figura 6) os pilares do tabuleiro sendo o P9 o mais próximo da Rua Prefeito José Carlos Lacerda, o P10 localizado na Rua Almirante Tamandaré e o P11 localizado próximo a ligação entre o tabuleiro e a rampa circular; (SANTOS, 2018)

Considerando os pilares de $\mathrm{P} 12$ ao $\mathrm{P} 15$ os pilares da rampa circular sendo o P12 o pilar de ligação com o tabuleiro e o P15 o pilar mais próximo ao centro da rampa na calçada, conforme identificação nas figuras 22, 23, 24, 25 e 26. (SANTOS, 2018)

A figura 5 ilustra a identificação dos Identificação dos Pilares P1 ao P5 da passa- 
rela em estudo.

Figura 5 - Identificação dos Pilares P1 ao P5 da passarela em estudo
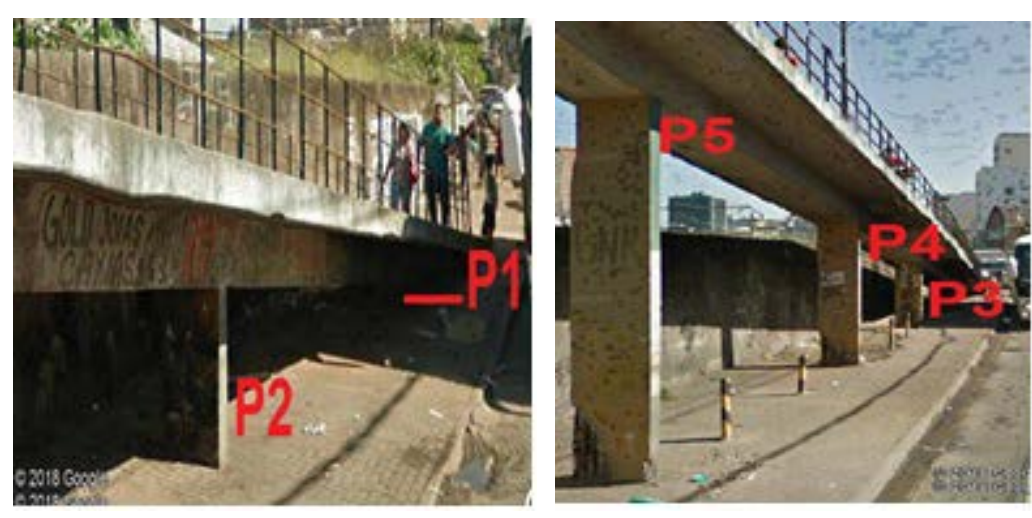

Fonte: (Adaptado Google Earth, 2018)

A figura 6 ilustra a identificação dos Identificação dos Pilares P6 ao P15 da passarela em estudo.

Figura 6 - Identificação dos pilares P6 ao P15 da passarela em estudo.
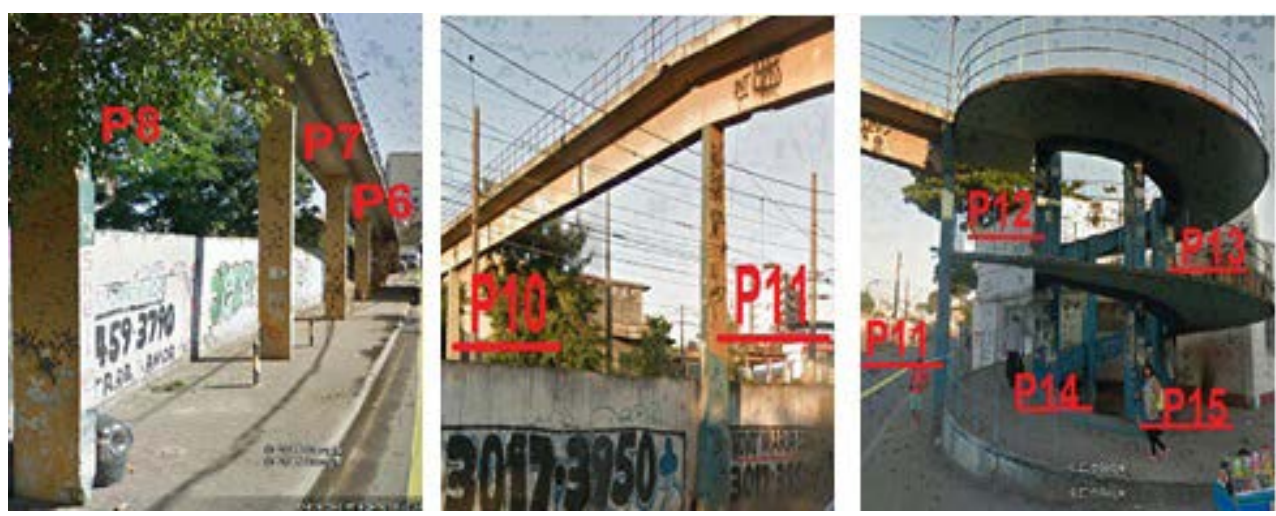

Fonte: (Adaptado Google Earth, 2018)

Considerando que a inspeção visual tem como objetivo verificar as condições de integridade da estrutura, verificou-se as seguintes considerações:

1) No pilar P1, não havia deterioração ou problemas visíveis;

2) No pilar P2 observou-se a degradação do concreto com exposição da armadu- 
ra, ocasionado pela queima de lixo próximo ao pilar.

3) Nos pilares P3, P8, P13 e P15 foram observados também a degradação do concreto, por provável carbonatação e armadura exposta com corrosão acentuada, perda de massa e aumento da seção ocasionadas por possível ação de íons cloreto, tendo em vista que o pilar se encontra em um meio agressivo de acúmulo de urina.

4) Nos pilares P4, P5, P7 e P10, apresentaram todos os problemas observados nos pilares P3, P8, P13 e P15 com o agravante que existe a ruptura de diversas barras de aço e estribos da armadura.

5) No pilar P6 pode-se observa-se um pontos de desprendimento do concreto, porém sem armaduras expostas.

Figura 7 - Figura ilustrativa dos problemas observados no pilar P4, P8 e P15.

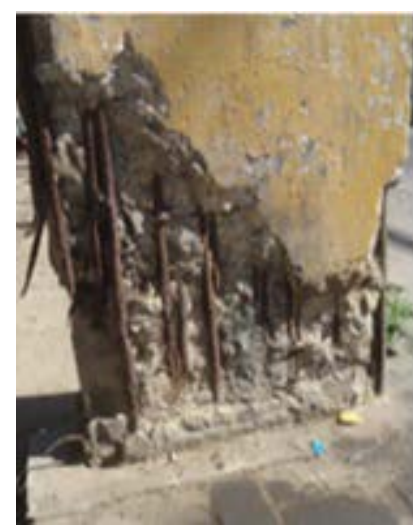

P4

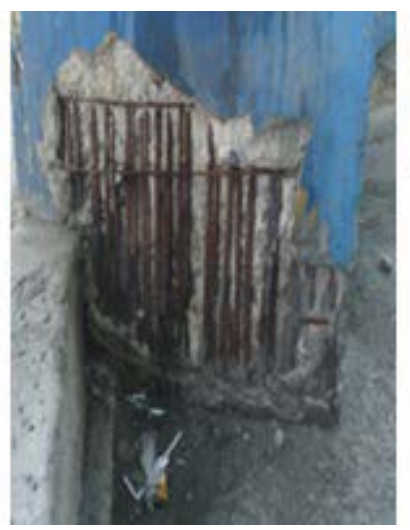

P8

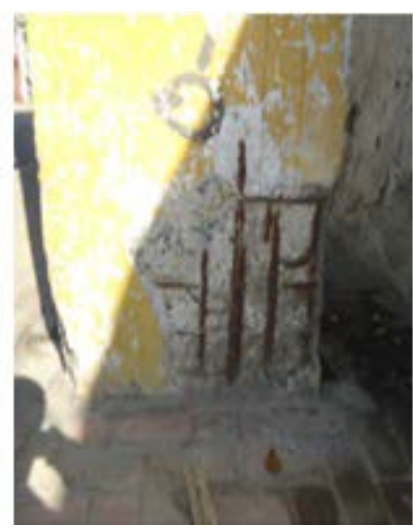

P15

Fonte: (SANTOS, 2018)

6) Na laje da rampa circular pode-se observar um ponto desprendimento de concreto com corrosão da armadura, devido à falta de cobrimento adequada da laje.

7) Na piso da laje do tabuleiro pode-se observar pontos com armadura exposta, possivelmente devido ao desgaste por uso.

8) Não foram observados problemas nas vigas das passarelas. 
Antes de realizar os reparos na passarela descrita os problemas apresentados deverão ser analisados para que haja uma melhor compreensão de cada patologia, para que as melhores soluções técnicas possam ser elaboradas.

Figura 8 - Problemas observados na laje do tabuleiro
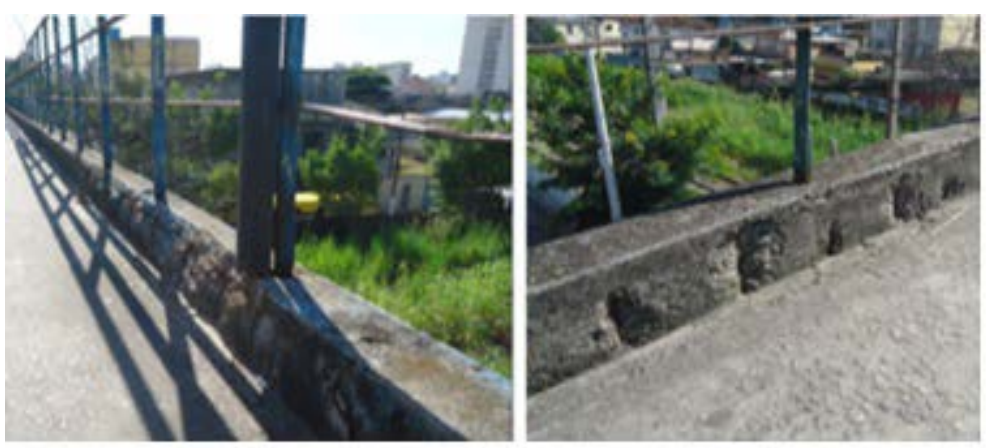

Fonte: (SANTOS, 2018)

Na passarela em estudo, tendo em vista que a corrosão é visível a olho nu, fazer os ensaios de TDR e impendância eletroquímica para estimar a extensão, o grau de corrosão, e a morfologia da corrosão, a fim de verificar se há possibilidade de recuperação dos pilares da estrutura.

É necessário medir a dureza e o grau de carbonatação do concreto, que na inspeção visual parece íntegro, para verificar se há a possibilidade de novas ocorrências de desprendimento de concreto da estrutura. Para tanto, utiliza-se o ensaio de esclerometria. Além disso, devido ao acúmulo de urina presente nos pilares, faz-se necessária realizar o ensaio de migração de íons cloreto.

\section{CONCLUSÃO}

O trabalho desenvolvido mostrou que existem diversas condições possíveis para o desenvolvimento da corrosão em estruturas de concreto armado, desde a falta de cobrimento ideal da armadura pelo concreto até o ataque por bactérias, por exemplo. 
No estudo de caso foi mostrado que estruturas com dimensões de cobrimento inadequadas, sem manutenção periódica, aliadas a ambientes agressivos (com alto índice de dióxido de carbono e cloreto de amônio) acabam sofrendo com a corrosão.

Além disso, no estudo de caso, foi mostrado que a passarela já possui problemas de corrosão, então deve ser estudada a viabilidade de aplicação de técnicas de recuperação e reforço dessas estruturas para evitar o risco de colapso.

\section{REFERÊNCIAS}

ALANI, Amir; PETERSEN, Andrew, CHAPMAN, Keith., Applications of a developed quantitative model in building repair and maintenance - case study. Facilities. v.19, n.5/6, 2001. p215-221.

ANDRADE, T.; COSTA E SILVA, A. J., Considerações sobre durabilidade, patologia e Manutenção das Estruturas, Tecomat - Tecnologia da Construção e Materiais Ltda, 2008, Disponível em: <https://ecivilufes.files.wordpress.com/2012/04/considerac3a7c3b5es-sobredurabilidade- patologia-e-manutenc3a7c3a3o-das-estruturas.pdf > Acesso em: 15 Agosto de 2018.

ARAÚJO, A.; PANOSSIAN, Z. Inspeção rotineira de estruturas de concreto armado expostas a atmosferas agressivas. Téchne, São Paulo, v. 1, n. 177, Dezembro 2011

ABNT - ASSOCIAÇÃO BRASILEIRA DE NORMAS TÉCNICAS. NBR 7584: Concreto Endurecido - Avaliação da dureza superficial pelo esclerômetro de reflexão - Método de Ensaio. Rio de Janeiro, 2012. 10 p.

FREIRE, Karla Regina Rattmann. Avaliação do desempenho de inibidores de corrosão em armaduras de concreto . 2005. 211 p. Dissertação (Mestrado em Engenharia) - Setor de Tecnologia, Universidade Federal do Paraná, Curitiba, 2005. Disponível em: <http://hdl.handle.net/1884/34720>. Acesso em: 25 set. 2017.

GENTIL, Vicente. Corrosão. 6. ed., Rio de Janeiro, LTC, 2011. 
HELENE, Paulo Roberto do Lago. Contribuição ao estudo de corrosão em armaduras de concreto armado . 1993. 248 p. Tese (Livre docência)- Escola Politécnica, Universidade de São Paulo, São Paulo, 1993. Disponível em: <http://www.phd.eng. br/wp-content/uploads/2014/07/TD1.pdf>. Acesso em: 12 fev. 2018.

MARQUES, Vínicius Silveira. Recuperação de estruturas submetidas à corrosão de armaduras: definição das variáveis que interferem no custo, 2015. 104 p. Projeto de pesquisa (Engenharia Civil) - Escola de Engenharia, Universidade Federal do Rio Grande do Sul, Porto Alegre, 2015. Disponível em: <http://hdl.handle.net/10183/138345>. Acesso em: 08 Agosto 2018.

MONTEIRO, P. Kumar Mehta e Paulo J. M. Concreto: Microestrutura, Propriedades e Materiais. 3. ed. São Paulo: IBRACON, v. 1, 2002

PELLIZZER, Giovanni Pais. Análise mecânica e probabilística da corrosão de armaduras de estruturas de concreto armado submetidas à penetração de cloretos. 2015. Dissertação (Mestrado em Estruturas) - Escola de Engenharia de São Carlos, Universidade de São Paulo, São Carlos, 2015. doi:10.11606/D.18.2015.tde-08042015-093036. Acesso em: 25 set. 2017.

RIBEIRO, Daniel Véras et al. Corrosão em estruturas de concreto armado: teoria, controle e métodos de análise. 1. ed. Rio de Janeiro: Elsevier, 2014.

ROCHA, Ivan. Corrosão em estruturas de concreto armado. Revista Espcializa OnLine IPOG, Goiânia, Edição n 10, Vol. 01/2015, Dezembro 2015.

SANTOS, Lourdimine. Avaliação da resistividade elétrica do concreto como parâmetro para a previsão da iniciação da corrosão induzida por cloretos em estruturas de concreto . 2006. 178 p. Dissertação (Mestrado em estruturas e construção civil) - Faculdade de Tecnologia, Universidade de Brasília, Brasília, 2006. Disponível em: <http://repositorio.unb.br/handle/10482/5188>. Acesso em: 16 fev. 2018. 
passarelas sobre linha férrea no Centro da cidade de Duque de Caxias/RJ, Trabalho de Conclusão de Curso, Departamento de Engenharia Civil, CEFET-RJ, 2018.

VILASBOAS, José Marcílio Ladeia. Durabilidade das edificações de concreto armado em Salvador: uma contribuição para a implantação da NBR: 6118/2003 . 2004. 231 p. Dissertação (Mestrado profissional em gerenciamento e tecnologia ambiental no processo produtivo) - Escola Politénica, Universidade Federal da Bahia, Salvador, 2004. Disponível em: <http://www.teclim.ufba.br/site/material_online/dissertacoes/dis_jose_m_I_vilasboas.pdf>. Acesso em: 12 jul. 2018. 